\title{
Produção de farinha de minhoca da espécie Eisenia fetida (Savigny, 1826) como ferramenta na gestão de estercos
}

\author{
Production of earthworm meal from Eisenia fetida (Savigny, 1826) as a tool for the management of \\ manure
}

\author{
Beatriz Simões Valente, Eduardo Gonçalves Xavier \\ Universidade Federal de Pelotas
}

Resumo

O objetivo do estudo foi avaliar a produção de farinha de minhoca da espécie Eisenia fetida como ferramenta na gestão de estercos. O delineamento utilizado foi o inteiramente casualizado, com três tratamentos, constituídos por $100 \%$ esterco bovino (T1), 100\% esterco eqüino (T2) e $100 \%$ esterco de capivara (T3), cada um com cinco repetições. Foram inoculadas em cada unidade experimental, 50 minhocas adultas e cliteladas da espécie Eisenia fetida. As amostras coletadas foram submetidas às análises de nitrogênio total, proteína bruta, fósforo total, potássio e cálcio total. Os resultados demonstraram que a produção de farinha de minhoca é uma importante ferramenta na gestão de estercos, não apresentando nenhuma limitação de natureza ambiental. Os substratos esterco bovino, eqüino e de capivara resultam em uma farinha de minhoca com alto teor de proteína bruta. A composição proteica e mineral da farinha de minhoca são dependentes da qualidade e da forma de armazenamento do esterco. O planejamento da criação animal deve contemplar um local adequado de armazenamento de esterco a fim de manter a qualidade do substrato fornecido as minhocas.

Palavras-chave: bovino, eqüino, proteína bruta, produção animal, vermicompostagem

Abstract

A trial was conducted to evaluate the production of earthworm meal from Eisenia fetida as a tool for the management of manure. A completely randomized design was used. The treatments were: 100\% bovine manure (T1), 100\% equine manure (T2) and 100\% capybara manure (T3). Each treatment had five replications. A total of 50 adult and containing clitellum earthworms (Eisenia fetida) were inoculated in each experimental unity. The following analyses were performed: total nitrogen, crude protein, total phosphorus, potassium and total calcium. The results showed that the production of earthworm meal is an important tool for the management of different manure and it does not present any limitation of environmental nature. The substrates bovine manure, equine manure and capybara manure result in an earthworm meal containing a high content of crude protein. The proteic and mineral composition of earthworm meal are dependent on the quality and form of storage of the manure. The proper planning of the animal production system must contemplate an adequate place for the storage of the manure in order to maintain the quality of the substrate provided to the earthworms.

Keywords: bovine, equine, crude protein, animal production, vermicomposting. 


\section{INTRODUÇÃO}

O descarte inadequado de resíduos orgânicos é uma problemática crescente a nível mundial. O elevado volume de estercos animais, gerados por diferentes sistemas de criação, tem uma parcela importante na contaminação dos solos e das águas quando depositados em locais inadequados. Entretanto, em decorrência da implantação de leis mais severas, que valorizam o gerenciamento ambiental, tem havido uma conscientização gradual dos efeitos nocivos provocados por esse despejo contínuo de resíduos líquidos e sólidos no meio ambiente (VALENTE et al., 2014).

A contaminação do meio ambiente pelos estercos pode ser amenizada por meio de adoção de prática simples de tratamento e gerenciamento desses resíduos. A vermicompostagem é uma alternativa viável para a redução desses impactos ambientais por ser uma técnica de tratamento mais rápida, menos dispendiosa financeiramente e mais econômica energeticamente (EASTMAN et al., 2001). O processo converte os resíduos orgânicos em dois valiosos produtos, o fertilizante orgânico (LALANDER et al., 2015) e a biomassa de minhoca, que pode ser usada como fonte de proteína na alimentação animal (MOMBACH et al., 2014). Vários pesquisadores têm demonstrado o grande potencial da Eisenia fetida como fonte proteica não convencional (IBÁÑEZ et al., 1993; VIELMARONDÓN et al., 2003; VIEIRA et al., 2004; TURRUELLA et al., 2006; ANTONIOLLI et al., 2009; ROMERO et al., 2010). Corroborando com as afirmações, alguns estudos vêm demonstrando o potencial da farinha de minhoca em substituição à farinha de pescado tradicional na alimentação de peixes (VALENTE et al., 2015). Rotta et al. (2003) verificaram em pós-larvas de tilápias, que o nível de $20 \%$ de farinha de minhoca na dieta promoveu maior ganho em massa. Da mesma forma, para juvenis de carpa (Cyprinus carpio), este mesmo nível de substituição proporcionou melhora nos parâmetros de crescimento e, consequentemente, maiores valores de massa média final, taxa de eficiência proteica e de crescimento específico e menor valor de conversão alimentar (RAWLING et al. 2012). Em estudo mais recente, Mombach et al. (2014) verificaram que a farinha de minhoca pode ser incluída em até $30 \%$ na dieta de juvenis, sem comprometer o crescimento dos peixes.

As primeiras técnicas de fabricação da farinha se baseavam na desidratação da minhoca por meio da liofilização, que é um processo caro no que se refere ao tipo e manutenção dos equipamentos utilizados. Atualmente, técnicas como a desidratação em estufa e em forno de microondas tem sido testadas. Valente et al. (2015) avaliaram o forno de microondas e a estufa na desidratação da biomassa de minhoca e verificaram que não houve diferença significativa entre os teores de proteína bruta da farinha de minhoca da espécie Eisenia fetida. Além disso, os autores concluíram que a substituição da estufa com circulação de ar forçada pelo forno de microondas na preparação da farinha de minhoca acelera o processo de desidratação. .

Contudo, há necessidade de realizar estudos relacionados à composição bromatológica, ao processamento e a conservação da farinha de minhoca (MOMBACH et al., 2014).

Objetivou-se avaliar a produção de farinha de minhoca da espécie Eisenia fetida (Savigny, 1826) como ferramenta na gestão de estercos.

\section{MATERIAL E MÉTODOS}

O experimento foi desenvolvido no Laboratório de Biologia do Departamento de Solos (DS) da Faculdade de Agronomia Eliseu Maciel (FAEM) da Universidade Federal de Pelotas (UFPEL), localizado no município de Capão do Leão/RS.

As unidades experimentais constaram de vasos com capacidade de 1,5 L. O delineamento utilizado foi o inteiramente casualizado, com três tratamentos, constituídos por $100 \%$ esterco bovino (T1), $100 \%$ esterco eqüino (T2) e $100 \%$ esterco de capivara (T3), cada um com cinco repetições. O esterco bovino foi proveniente de vacas da raça Jersey, pertencentes a Embrapa Clima Temperado, situada no município de Pelotas/RS. O esterco de capivara foi coletado na mesma empresa. O esterco eqüino foi obtido no Hospital Veterinário da Faculdade de Medicina Veterinária da Universidade Federal de Pelotas, campus Capão do Leão/RS.

Foram inoculadas em cada unidade experimental, 50 minhocas adultas e cliteladas da espécie Eisenia fetida (Savigny, 1826). O teor de umidade foi verificado a cada 15 dias, através do "teste da 
mão" conforme método de Cooper et al. (2010), em que o teor ótimo de água foi determinado pela formação de uma massa firme, quando o substrato foi comprimido pelas mãos. Utilizou-se palha de gramínea seca como cobertura dos substratos a fim de evitar a perda de umidade.

A produção de farinha de minhoca foi realizada 90 dias após a instalação do experimento. Para o processamento das amostras foram utilizadas 40 minhocas da espécie Eisenia fetida (Savigny, 1826) de cada tratamento, que foram previamente colocadas em peneira e lavadas com água destilada. A segunda etapa da fabricação da farinha compreendeu a imersão das minhocas em béqueres contendo $300 \mathrm{~mL}$ de água destilada, por aproximadamente 4 horas, para o esvaziamento do seu tratodigestório. As minhocas receberam tratamento térmico em forno de microondas da marca Panasonic ${ }^{\circledR}$, com potência nominal de $900 \mathrm{~W}$ e frequência de operação de $2.450 \mathrm{MHz}$, por 15 minutos, sendo revolvidas a cada cinco minutos a fim de desidratá-las uniformemente. As amostras desidratadas foram trituradas com o auxílio de um moinho da marca Marconi ${ }^{\circledR}$, modelo MA 048.

As análises da composição química foram realizadas em triplicata, sendo que a primeira amostragem correspondeu aos substratos iniciais esterco bovino, eqüino e capivara conforme apresentada na Tabela 1. A segunda amostragem refere-se ao teor nutricional das farinhas de minhoca.

No Laboratório de Nutrição Animal do Departamento de Zootecnia da FAEM da UFPEL foi realizada a avaliação de nitrogênio total $(\mathrm{N})$ pela digestão das amostras em ácido sulfúrico e posterior destilação em aparelho Kjedahl, conforme descrito por Silva e Queiroz (2004). O teor de proteína bruta (PB) foi calculado aplicando o fator 6,25. No Laboratório de Química do Solo do Departamento de Solos da FAEM da UFPEL foram analisados os teores de fósforo total (P), potássio (K) e cálcio total (Ca) conforme metodologia descrita por Tedesco et al. (1995).

Tabela 1. Composição química dos substratos fornecidos as minhocas da espécie Eisenia fetida. Capão do Leão, RS, 2015.

\begin{tabular}{|c|c|c|c|c|}
\hline \multirow{3}{*}{ Substratos } & \multicolumn{4}{|c|}{ Composição química } \\
\hline & \multirow[t]{2}{*}{$\mathrm{N}(\%)$} & $\mathrm{P}$ & $\mathrm{K}$ & $\mathrm{Ca}$ \\
\hline & & \multicolumn{3}{|c|}{ - $\mathrm{g} \mathrm{kg}^{-1}$ - } \\
\hline Esterco bovino & $0,54 \pm 0,02$ & $0,85 \pm 0,04$ & $2,51 \pm 0,07$ & $2,96 \pm 0,08$ \\
\hline Esterco equino & $0,92 \pm 0,06$ & $17,13 \pm 1,03$ & $9,30 \pm 0,09$ & $29,49 \pm 2,03$ \\
\hline Esterco de capivara & $1,54 \pm 0,33$ & $6,65 \pm 1,01$ & $17,59 \pm 0,09$ & $7,37 \pm 1,06$ \\
\hline
\end{tabular}

Valores médios de três replicatas.

Os dados referentes às variáveis estudadas foram submetidos à análise de variância (ANOVA), com o uso do programa estatístico "Statistical Analysis System" versão 9.1 (SAS Institute Inc. 2002-2003), sendo as médias analisadas pelo teste de Duncan a 5\%.

\section{RESULTADOS E DISCUSSÃO}

Na Tabela 2, pode ser observado que o teor de proteína bruta da farinha de minhoca, alimentadas com esterco eqüino $(57 \%)$, foi significativamente superior $(\mathrm{P}<0,05)$ aos demais tratamentos, estercos bovino (42\%) e capivara (44\%). A preferência das minhocas pelo esterco equino pode estar relacionada à presença de vegetais fibrosos, o que melhorou a textura e a aeração, favorecendo o seu desenvolvimento (BASSACO et al., 2015). Na Tabela 1, pode-se verificar uma maior concentração de $\mathrm{N}$ no esterco de capivara $(1,54 \%)$ o que provavelmente resultaria em uma maior porcentagem de proteína bruta na farinha de minhoca, que foram alimentadas com esse substrato. No entanto, esse fato não foi observado possivelmente devido a menor digestibilidade do esterco capivara e consequentemente uma maior excreção de $\mathrm{N}$ nas fezes.

De outra forma, o valor de $42 \%$ de proteína bruta da farinha de minhoca submetidas ao tratamento esterco bovino discorda de Turruela et al. (2006), que verificaram um teor de proteína 
bruta de $62,37 \%$ na farinha de minhoca da espécie Eisenia fetida alimentadas com esterco bovino. Em estudo mais recente, Valente et al. (2015) também encontraram um teor mais alto de proteína bruta $(59,56 \%)$ na farinha de minhoca da espécie Eisenia fetida que receberam esterco bovino como substrato. Isso sugere que outros fatores como a qualidade e a forma de armazenamento do esterco possam interferir no teor de proteína bruta da farinha, além do tipo de alimentação fornecida as minhocas conforme afirmaram Ibáñez et al. (1993). É importante salientar que o esterco bovino foi coletado no campo e estava exposto ás intempéries, o que possivelmente afetou a concentração de $\mathrm{N}$ fornecido na dieta das minhocas. Além disso, Loureiro et al. (2007) salientam que a qualidade dos estercos varia conforme o regime alimentar do bovino e o manejo do rebanho, o que dificulta comparações com outros resultados.

Tabela 2. Composição nutricional das farinhas de minhoca da espécie Eisenia fetida (Savigny, 1826) alimentadas com diferentes resíduos animais. Capão do Leão, RS, 2015.

\begin{tabular}{lcccc}
\hline \multirow{2}{*}{ Tratamentos } & \multicolumn{4}{c}{ Composição nutricional } \\
\cline { 2 - 5 } & PB (\%) & P & K & Ca \\
\cline { 2 - 5 } & & - & & \\
\cline { 2 - 5 } & $42,0 \pm 1,56^{\mathrm{b}}$ & $6,4 \pm 1,67^{\mathrm{a}}$ & $5,4 \pm 0,67^{\mathrm{b}}$ & $4,0 \pm 0,34^{\mathrm{a}}$ \\
T1 (esterco bovino) & $57,0 \pm 2,45^{\mathrm{a}}$ & $7,0 \pm 1,23^{\mathrm{a}}$ & $6,6 \pm 0,45^{\mathrm{a}}$ & $4,0 \pm 0,45^{\mathrm{a}}$ \\
T2 (esterco eqüino) & $44,0 \pm 2,57^{\mathrm{b}}$ & $5,0 \pm 0,34^{\mathrm{b}}$ & $7,0 \pm 0,89^{\mathrm{a}}$ & $3,4 \pm 0,13^{\mathrm{a}}$ \\
\hline
\end{tabular}

Médias seguidas pela mesma letra dentro da mesma coluna não diferem entre si pelo teste de Duncan a $5 \%$.

Considerando os teores de minerais, pode-se observar que o $\mathrm{P}$ da farinha de E. fetida, resultante dos tratamentos estercos bovino $\left(6,4 \mathrm{~g} \mathrm{~kg}^{-1}\right)$ e eqüino $\left(7,0 \mathrm{~g} \mathrm{~kg}^{-1}\right)$ foi significativamente superior $(\mathrm{P}<0,05)$ as alimentadas com o substrato capivara $\left(5,0 \mathrm{~g} \mathrm{~kg}^{-1}\right)$. Diferentemente, verificou-se que o teor de $\mathrm{K}$ da farinha de minhoca, alimentadas com estercos de capivara $\left(7,0 \mathrm{~g} \mathrm{~kg}^{-1}\right)$ e de eqüino $\left(6,6 \mathrm{~g} \mathrm{~kg}^{-1}\right)$, foram significativamente superiores as que receberam esterco bovino $\left(5,4 \mathrm{~g} \mathrm{~kg}^{-1}\right)$. As diferenças encontradas possivelmente foram devidas aos componentes da dieta fornecida aos animais, ao manejo e aspectos fisiológicos de cada espécie.

\section{CONCLUSÕES}

A produção de farinha de minhoca da espécie Eisenia fetida é uma importante ferramenta na gestão de estercos. ambiental.

O processo de produção da farinha de minhoca não apresenta nenhuma limitação de natureza

Os substratos esterco bovino, eqüino e de capivara resultam em uma farinha de minhoca com alto teor de proteína bruta.

A composição proteica e mineral da farinha de minhoca são dependentes da qualidade e da forma de armazenamento do esterco.

O planejamento da criação animal deve contemplar um local adequado de armazenamento de esterco a fim de manter a qualidade do substrato fornecido as minhocas.

\section{REFERÊNCIAS}


ANTONIOLLI, Z.I.; STEFFEN, G.P.K.; STEFFEN, R.B. Utilização de casca de arroz e esterco bovino como substrato para a multiplicação de Eisenia fetida Savigny (1826). Ciência Agrotécnica, v. 33, n. 3, p. 824-830, 2009.

BASSACO, A.C.; ANTONIOLLI, Z.I.; BRUM JUNIOR, B.DE.S.; ECKHARDT, D.P.; MONTAGNER, D.F.; BASSACO, G.P. Caracterização química de resíduos de origem animal e comportamento de Eisenia andrei. Ciência e Natura, v. 37, n. 1, p. 45-51, 2015.

COOPER, M.; ZANON, A.R.; REIA, M.Y.; MORATO, R.W. 2010. Compostagem e reaproveitamento de resíduos orgânicos agroindustriais: teórico e prático. Piracicaba: ESALQ, 2010. 35 p.

EASTMAN, B.R.; KANE, P.N.; EDWARDS, C.A.; TRYTEK, L.; GUNADI, B.; STERMER, A.L.; MORLEY, J.R. The effectiveness of vermiculture in human pathogen reduction for USEPA biosolids stabilization. Compost Science Utilization, v. 9, n. 1, p. 38-49, 2001.

IBÁÑEZ, I.A.; HERRERA, C.A.; VELÁSQUEZ, L.A.; HEBEL, P. Nutritional and toxicological evaluation on rats of eartworm (Eisenia fetida) meal as protein source for animal feed. Animal Feed Science and Technology, v. 42, p. 165-172, 1993.

LALANDER, C.H.; KOMAKECH, A.J.; VINNERAS, B. Vermicomposting as manure management strategy for urban small-holder animal farms - Kampala case study. Waste Management, v. 39, p. 96103, 2015.

LOUREIRO, D.C.; AQUINO, A.M.DE; ZONTA, E.; LIMA, E. Compostagem e vermicompostagem de resíduos domiciliares com esterco bovino para a produção de insumo orgânico. Pesquisa Agropecuária Brasileira, v. 42, n. 7, p. 1043-1048, 2007.

MOMBACH, P.I.; PIANESSO, D.; ADORIAN, T.J.; UCZAY, J.; LAZZARI, R. Farinha de minhoca em dietas para juvenis de jundiá. Pesquisa Agropecuária Tropical, v. 44, n. 2, p. 151-157, 2014.

RAWLING, M.; MERRIFIELD, D.; SNELLGROVE, D.; KÜHLWEIN, H.; ADAMS, A.; DAVIES, S. Haemato-immunological and growth response of mirror carp (Cyprinus carpio) fed a tropical earthworm meal in experimental diets. Fish \& Shellfish Immunology, v. 32, p. 1002-1007, 2012.

ROMERO, B.A.; BOU-MAROUN, E.; REPARET, J.M.; BLANQUET, J.; CAYOT, N. Impact of lipid extraction on the dearomatisation of an Eisenia foetida protein powder. Food Chemistry, v. 119, p. 459466, 2010.

ROTTA, M.A.; AFONSO, L.O.B.; PENZ JÚNIOR, A.M.; WASSERMANN, G.J. Uso da farinha de minhoca como alimento para pós-larvas de tilápia. Corumbá: Embrapa Pantanal, 2003. 35p. (Boletim de Pesquisa e Desenvolvimento 45).

SAS Institute Inc. 2002-2003. Statistical analysis system. Release 9.1. (Software). Cary. USA.

SILVA, D.J.; QUEIROZ, A.C.DE. Análise de Alimentos: Métodos Químicos e Biológicos. Viçosa: Universidade Federal de Viçosa, 2004. 235p.

TEDESCO, M.J.; GIANELLO, C.; BISSANI, C.A.; BOHNEN, H.; VOLKWWEISS, S.J. Análises de solo, plantas e outros materiais. POA: Faculdade de Agronomia/UFRGS, 1995.174p. 
TURRUELLA, E.P.; GOMES, J.C.C.; MORSELLI, T.B.G.A.; SCHWENGBER, J.E.; MEDEIROS, C.A.B.de. Características da farinha de minhoca para consumo animal e humano. In: ENCONTRO DE INICIAÇÃO CIENTÍFICA E PÓS-GRADUAÇÃO DA EMBRAPA CLIMA TEMPERADO, 2006, Pelotas. Anais... Pelotas: Embrapa Clima Temperado, 2006. 174p.

VALENTE, B.S.; XAVIER, E.G.; MORAES, P.DE.O.; PILOTTO, M.V.T.; PEREIRA, H.DA.S. Compostagem em pilhas e vermicompostagem no tratamento da mistura de cama de aviário e dejetos líquidos de bovinos leiteiros. Revista AUGMDOMUS, v. 6, p. 111-122, 2014.

VALENTE, B.S.; XAVIER, E.G.; MORSELLI, T.B.G.A.; LOPES, M. Proteina bruta da farinha de minhoca da espécie Eisenia fetida (Savigny, 1826) submetida a diferentes tratamentos térmicos. Revista Brasileira de Higiene e Sanidade Animal, v. 9, n. 1, p. 102-107, 2015.

VIEIRA, M.DE.L.; FERREIRA, A.S.; DONZELLE, J.L. Digestibilidade da farinha de minhoca para suínos. Boletim de Indústria Animal, v. 61, n. 1, p. 83-89, 2004.

VIELMA-RONDÓN, R.; OVALLES-DURÁN, J.F.; LEÓN-LEAL, A.; MEDINA, A. Valor nutritivo de la harina de lombric (Eisenia foetida) como fuente de aminoácidos y su estimación cuantitativa mediante cromatografía en fase reversa (HPLC) y derivatización precolumna con o-ftaldehido (OPA). Ars Pharmaceutica, v. 44, n. 1, p. 43-58, 2003. 